\title{
РЕЧЕВОЕ ВОЗДЕЙСТВИЕ В СПОРТИВНОМ ДИСКУРСЕ
}

\section{LINGUISTIC MANIPULATION IN SPORT DISCOURSE}

\section{N. Medvedeva}

Summary: The article represents the attempt to analyze linguistic manipulation in sport discourse in Russian and foreign sport newspapers for eliciting manipulative factors on people's consciousness.

Keywords: linguistic manipulation, sport discourse, speech strategy.
Медведева Нигина Абдурахимовна

Аспирант, Московский городской педагогический университет bear74@inbox.ru

Аннотация: В статье рассматривается вопрос о речевом воздействии в спортивном дискурсе. Проводится анализ спортивных статей российских и зарубежных газет с целью выявления факторов воздействия на сознание масс.

Ключевые слова: речевое воздействие, речевое/языковое манипулирование, спортивный дискурс, языковые приемы.

ведение, осуществляемое разнообразными речевыми средствами» [2, с. 54]. Иными словами «Воздействуя на реципиента, мы стремимся "спровоцировать" его поведение в нужном нам направлении, найти в системе его деятельности "слабые точки", выделить управляющие ею факторы и избирательно воздействовать на них» [7, с. 103]. Таким образом, автор создает речевое сообщение с надеждой на определенный эффект, а именно, формирование общественной позиции и мировоззрения читателя, его мышления и действия.

Не требует доказательств тот факт, что речевое воздействие происходит при помощи вербальных характеристик языка. Язык играет большую роль в деятельности людей, определяет их картину мира, следовательно, является средством воздействия на адресата, при котором происходит влияние, а порой и навязывание заданных векторов на определенное мировоззрение. Таким образом, умелое пользование языковыми средствами играет большую роль в убеждении. Управление сознанием в процессе коммуникации, осуществляется при помощи речевых приемов и языковых средств, называемых иначе речевым (языковым) манипулированием. Необходимо отметить, что многие исследователи (Г.Ф. Александров, Б.М. Кедров, Н.Я. Марр, Ж. Вандриес) не разграничивают данные понятия, несмотря на существование дихотомии «язык - речь» [Соссюр, 1999]. «Речевое воздействие» это воздействие на человека при помощи речи с целью убедить его сознательно принять решение о каком-либо действии, передаче информации и т. д., а «манипулирование» - это воздействие на человека с целью побудить его сообщить информацию, совершить поступок, изменить свое поведение и т. д. неосознанно или вопреки его собственному мнению, намерению» [7, с. 67]. При манипулировании языковая составляющая взаимодействует с психологическими компонентами речевой деятельности, «которые вынуждают адресата некритично воспринимать речевое сообщение, способствует возникновению в его сознании определенных иллюзий и 
заблуждений, провоцируют его на совершение выгодных для манипулятора поступков» [3, с. 566].

При рассмотрении речевого воздействия выделяют следующие факторы:

1. воздействие происходит скрытно от субъекта;

2. происходит подчинение манипулируемого своей воле, интересы манипулируемого не принимаются во внимание;

3. манипулятор обучен определенным знаниям, а именно: искусному владению словом, психологическим навыкам, владению особой речевой организацией текста, которая приводит сознание собеседника к заблуждению, происходит иллюзия самостоятельно принятого решения при отсутствии защитной реакции у субъекта воздействия [4].

При анализе статей с сайта "Euronews", можно заметить использование авторами скрытых видов манипуляции, имеющие подзаголовок срочности, массированной повторяемости и эмоциональном воздействии спортивных новостей. На сегодняшний день существует огромное количество приемов психологического воздействия. При создании сообщения особое внимание отводится правильной выработке аргументов и умело подобранному речевому инструментарию, которые помогают подтвердить правильность авторской точки зрения и в конечном счете способствуют реализации поставленной цели манипулятора. Автор статьи подводит реципиента к правильному принятию решения. Также, не менее важным фактором является для кого создается сообщение. Это может быть целевая аудитория, широкая общественность или частное лицо.

Так, несмотря на успешное проведение мирового кубка по футболу в России в 2018 г., зарубежные спортивные сайты до сих пор настойчиво предоставляют факты, доказывающие передачу взятки руководству ФИФА представителями Российской Федерации, которые повлияли на выбор места проведения мирового кубка по футболу 2018 и 2020 гг.: «An indictment in the US District Court filed this week gave details of alleged bribes paid to top FIFA officials to vote for Russia and Qatar to the host the football tournaments in 2018 and 2022 respectively» [9]. (На этой неделе, обвинители окружного суда США сообщили подробности о подкупах руководства ФИФА при голосовании за Россию и Катар, как места проведения футбольного чемпионата в 2018 и 2022 годах соответственно) [здесь и далее перевод наш - Н.М.]. В данном примере читатель не может усомниться в истинности предлагаемой информации, т.к. для европейских граждан, американский суд является органом справедливости и честности, и, как известно, чем более авторитетен источник, тем ему больше доверяют. Таким образом, подобные многократно повторяемые «сенсационные разоблачения» различных изданий дискредитируют образ России, заставляют читателя поверить в истинность сообщений и навязывают угодную для Запада точку зрения.

Помимо эмотивной стороны, в спортивном дискурсе часто используются броские, кричащие пропагандистские заголовки с упоминанием именитых фамилий спортсменов и их тренеров. Например, «Первая важная битва Плющенко и Тутберидзе: Трусова против Валиевой» [1]. Помимо соперничества между известными тренерами мира по фигурному катанию, посредством скандалов, происходит своего рода и популяризация этого вида спорта. Многие любители данного вида спорта пытаются увлечься этим направлением и подражать фигуристкам в исполнении спортивных элементов. Подражание, как известно, является также распространенным приемом при манипулировании массовым сознанием.

Довольно часто, в спортивном дискурсе используется прием градации, когда автор также на эмоциональном уровне делится успехами своей любимой команды. «ДААА! Российская молодежка едет на Евро! Красавцы!!!!!!», «Молодежная сборная России в шаге от попадания на Евро-2021: все голы матча» [6]. В данном примере автор сокращает дистанцию с читателем, выводит его на диалогизацию, которая оказывает огромное воздействие на читателя.

В отличие от других видов дискурса (рекламного, политического), спортивный дискурс не вызывает у читателя негативных эмоций, а способствует возникновению интереса и внимания к спортивному событию. Активное применение речевого манипулирования в спортивном дискурсе обусловлено рядом факторов: прежде всего политическим влиянием, авторской эмоциональной презентацией материала.

Примером этому может служить следующий заголовок на веб-сайте The Gardian: «Russia's cyber-attack plan of familiar pattern» («План кибер атаки России по знакомому сиенарию») [9]. В данном примере демонстрируется пример взаимодействия политического и спортивного дискурсов, несмотря на то что газета заявляет: «We have no shareholders or billionaire owner, meaning our journalism is free from commercial and political influence - this makes us different. We are determined to uphold our reputation for producing urgent, powerful, high-impact reporting on the environment that's read by around the world» [9]. (У нас нет акционеров и собственника миллиардера, а это означает, что журнализм свободен от коммерческого и политического влияния. .... ны начелены на поддержание нашей репутации для предоставления срочной, весомой, влиятельной информации, происходящей в мире, которую читают во всем мире). В статье рассматривается вопрос о систематических атаках России на зарубежные избирательные комиссии и олимпийские комитеты. В самом начале статьи автор пытается «отгородить» себя 
от дельнейших нападок, где в качестве доказательств приводятся доводы одного из членов правительства Великобритании без указании его имени: «Russia planned cyber-attack on Tokyo Olympics, says UK» (Россия запланировала кибератаку на Олимпийский комитет Токио, заявляет Великобритания), тем самым доказывая неоспоримость своих предположений. В этой же статье: «In the aftermath of Moscow's hacking of the 2016 US election, many analysts expected the GRU to be punished. After all, Russia's powerful military spy agency had been caught red-handed. The FBI indicted several GRU hackers in humiliating fashion. The spies who stole Democratic party emails - tens and thousands of them - were named and shamed». (ПОСЛЕ хакерской атаки Москвы в 2016 году на выборах президента в США, многие аналитики предполагали, что ГРу России будет наказано. В коние концов влиятельное российское агентство по шпионажу было поймано на месте преступления. ФБР обвинило нескольких хакеров ГРУ, в унизительной манере. Шпионы укравшие электронные сообщения демократов - десятки тысяч писем - были названы и пристыжены). Как мы видим, в статье приводится несколько ссылок на участников неопределенных референтных групп, которые используются для развенчивания сомнений, которые придают значимость и массовость выражаемого мнения. Кроме того, в связи с проанализированными примерами важно отметить, что экспрессивная и эмоциональная окрашенность выражений значительно повышает эффективность и значимость подаваемого материала.

Таким образом, основным механизмом воздействия на сознание людей в спортивном дискурсе являются психологические и психолингвистические факторы, способствующие читателю некритично воспринимать спортивную информацию. Приемы, используемые автором спортивной статьи, делают ее незабываемой, эмоционально окрашенной, а также формируют общественную позицию и взгляды читателей.

\section{ЛИТЕРАТУРА}

1. Борисов А. Первая важная битва Плющенко и Тутберидзе: Трусова против Валиевой https://www.gazeta.ru/sport/2020/10/09/a_13314121.shtml (дата обращения 11.10.2020).

2. Гришечко Е.Г. Определение понятия речевого воздействия и виды этого воздействия. Гуманитарные и социальные науки. 53-59 с.

3. Завьялова 0.Н. Речевое (языковое) манипулирование. Культура русской речи: энциклопедический словарь-справочник/ под ред. Л.Ю. Иванова, А.П. Сковородникова, Е.Н, Ширяева и др. М.: Флинта: Наука, 2007. 566-570 с.

4. Кара-Мурза С.Г. Манипуляция сознанием [Электронный ресурс]: http://www.kara-murza.ru/books/manipul/manipulation.pdf (дата обращения 15.08.2020).

5. Копнина Г.А. Речевое манипулирование: уч. пособие. М.: Флинта, 2012. 170 с.

6. Молодежная сборная в шаге от попадания на Евро-2012: все голы матча [Электронный ресурc] https://www.sport-express.ru/football/juniors/news/ molodezhnaya-sbornaya-rossii-v-shage-ot-popadaniya-na-evro-2021-vse-goly-matcha-1719076/ (дата обращения 13.10.20).

7. Леонтьев А.А. Психология воздействия в массовой коммуникации. Язык средств массовой коммуникации: Уч. пособие по специализации. Ч. 2. М.: Издво Моск. ун-та, 2004. 99-105 с.

8. Стернин И.А. Основы речевого воздействия: учеб. издание. Воронеж: Истоки, 2012. 178 с.

9. Luke Harding. Russia rejects new World Cup bribery charges 'conspiracy theory'» Euronews, https://www.euronews.com/2020/04/08/russia-rejects-new-worldcup-bribery-charges-as-conspiracy-theory (дата обращения 09.11.2020).

(с Медведева Нигина Абдурахимовна (bear74@inbox.ru). 